\title{
Threshold dose of liver tumor promoting effect of $\beta$-naphthoflavone in rats
}

\author{
Hitomi Hayashi'1,2, Eriko Taniai1,2, Reiko Morita ${ }^{1,2}$, Atsunori Yafune ${ }^{1,2}, K^{1}$ Kazuhiko Suzuki ${ }^{1}$, \\ Makoto Shibutani ${ }^{1}$ and Kunitoshi Mitsumori ${ }^{1}$ \\ ${ }^{1}$ Laboratory of Veterinary Pathology, Tokyo University of Agriculture and Technology, \\ 3-5-8 Saiwai-cho, Fuchu-shi, Tokyo 183-8509, Japan \\ 2United Graduate School of Veterinary Science, Gifu University, 1-1 Yanagido, Gifu-shi, Gifu 501-1193, Japan
}

(Received January 8, 2012; Accepted February 15, 2012)

\begin{abstract}
To determine the threshold dose of $\beta$-Naphthoflavone (BNF) that induces hepatocellular tumor promoting effects, reactive oxygen species (ROS) generation and thiobarbituric acid-reactive substance (TBARS) formation, and drug-metabolizing enzymes that protect against ROS generation, two-stage liver carcinogenesis model was used. Partial hepatectomized rats $(\mathrm{n}=11$ to 12$)$ were fed diets containing $0,0.03,0.06,0.125$ or $0.25 \%$ BNF for 6 weeks after an intraperitoneal injection of $N$-diethylnitrosamine (DEN) to initiate hepatocarcinogenesis. Histopathologically, glutathione $S$-transferase placental form (GST-P)-positive foci significantly increased in rats given $0.25 \%$ BNF. No marked changes in ROS production and TBARS contents were observed between the BNF treated and DEN alone groups. Realtime RT-PCR showed that the expression of Cypla1, Cypla2, Cyplb1 and Nqol significantly increased in the groups given $0.03 \%$ BNF or more, but Ugtla6, Akr7a3 and Gstm 1 significantly increased in the groups given $0.125 \% \mathrm{BNF}$ or more. Gpx2 and $Y c 2$ significantly increased in the groups given $0.06 \% \mathrm{BNF}$ or more and $0.25 \%$ BNF, respectively. Inflammation-related genes such as Ccl2, Mmp12, Serpinel and Cox-2 significantly increased in the $0.25 \% \mathrm{BNF}$ group. In immunohistochemistry, the number of cyclooxygenase-2 (COX-2)-positive cells increased in rats given $0.25 \%$ BNF. These results suggest that $0.25 \%$ $\mathrm{BNF}$ is the threshold dose for liver tumor promotion, and the fact that inflammation-related genes and COX-2 protein increased in the $0.25 \%$ BNF group strongly suggests that inflammation is involved in the liver tumor promoting effect of BNF in rats.
\end{abstract}

Key words: $\beta$-naphthoflavone, Threshold dose, Cyp1A inducer, Rat, Liver

\section{INTRODUCTION}

Oxidative stress has been recognized as an important facter affecting the pathogenesis of degenerative and inflammatory diseases, aging and cancer (Wiseman and Halliwell, 1996; Trush and Kensler, 1991). Especially, reactive oxygen Species (ROS) are considered to play an important role in the liver cancer, and ROS overproduction and subsequent oxidative DNA damage have been implicated to enhance the development of hepatocellular carcinomas that are caused by carcinogenic agents including hepatic $\mathrm{C}$ virus (Moriya et al., 2001), 2,3,7,8-tetrachlorodibenzo- $p$-dioxin (TCDD) (Lin et al., 2007) and metals (Asare et al., 2006). In addition, inflammation has also been recognized as a risk factor for carcinogenesis (Cervello and Montalto, 2006). Indeed, non-viral inflam- mation diseases of the liver including alcoholic hepatitis, hemochromatosis and primary biliary cirrhosis have been demonstrated to be related to the development of hepatocellular carcinomas (Cervello and Montalto, 2006).

$\beta$-Naphthoflavone (BNF) is a synthetic derivative of a naturally occurring flavonoid that selectively and strongly induces cytochrome P450 (CYP) 1A enzymes via aryl hydrocarbon receptor (AhR) activation (Guengerich and Liebler, 1985; Prochaska and Talalay, 1988). BNF does not have mutagenicity in Salmonella/microsome assay (Brown and Dietrich, 1979), but has a liver tumor promoting activity in a two-stage liver carcinogenesis bioassay in rats (Shoda et al., 2000a, 2000b). In our previous study, the number and area of glutathione $S$-transferase placental form (GST-P)-positive foci significantly increased in the rat given diet containing 0.5 or $1 \% \mathrm{BNF}$ for 6 weeks after

Correspondence: Kunitoshi Mitsumori (E-mail: mitsumor@cc.tuat.ac.jp) 
$N$-diethylnitrosamine (DEN) initiation treatment (Dewa et al., 2008). In microarray and real-time RT-PCR analysis of the liver, AhR gene battery such as Cypla1, Cypla2, Cyp1b1, Nqo1, Aldh3a1 and Ugtla6 as well as the transcriptional factor NF-E2-related factor2 (Nrf2)-regulated genes including Gstm1, Gpx2, Akr7a3 and Yc2 significantly increased in these BNF-treated rats compared to the DEN alone group. The enhancement of oxidative stress including microsomal ROS production, 8-hydroxydeoxyguanosine (8-OHdG), and thiobarbituric acidreactive substance (TBARS) suggested that such an oxidative stress played an important role in the BNF-induced hepatocarcinogenesis in rats (Dewa et al., 2008, 2009). In addition, our previous study demonstrated that inflammatory responses were also involved in the tumor promotion activity of BNF (Kuwata et al., 2011). However, the threshold dose of the liver tumor promoting effect of BNF in rats has not been clarified.

In the present study, we have performed a two-stage liver carcinogenesis bioassay in rats to identify the threshold dose of BNF that induces liver tumor-promoting effects.

\section{MATERIALS AND METHODS}

\section{Chemicals}

BNF (CAS No. 6051-87-2, purity 98\%) and DEN (CAS No. 55-18-5, purity 99\%) were purchased from Wako Pure Chemical Industries (Osaka, Japan) and Tokyo Kasei Kogyo (Tokyo, Japan), respectively.

\section{Animals and Experimental Design}

Five-week-old male F344 rats were purchased from Japan SLC, Inc. (Shizuoka, Japan), maintained in an air-conditioned room with a twelve-hour light/dark cycle (room temperature, $23 \pm 3^{\circ} \mathrm{C}$; relative humidity, $55 \pm 15 \%$ ), and given free access to a basal diet (Oriental MF; Oriental Yeast, Tokyo, Japan) and tap water. The animals received human care in accordance with the Guide for Animal Experimentation of the Tokyo University of Agriculture and Technology.

After a one-week acclimatization period, a mediumterm liver carcinogenesis bioassay (Ito et al., 2003) was performed according to the following procedure: First, all rats were treated with an intraperitoneal injection of DEN at a dose of $200 \mathrm{mg} / \mathrm{kg}$ body weight, followed by treatment with 0 (DEN alone), 0.03, 0.06, 0.125 and $0.25 \%$ BNF in diet for six weeks starting two weeks after DEN treatment. To enhance hepatocellular proliferation, the rats were subjected to two-third partial hepatectomy in the first 3 weeks of commencing the experiment. The ration- al for dosage was determined based on the result of our previous study in which $0.5 \%$ BNF for 6 weeks showed tumor promoting effects in the liver of rats (Dewa et al., 2008). At the end of the experiment, the rats were euthanized by exsanguination under ether anesthesia, and their livers were excised and weighed. The sliced liver samples were fixed in either $10 \%$ phosphate-buffered formalin for histopathological and immunohistochemical evaluations or were frozen in liquid nitrogen and stored at $-80^{\circ} \mathrm{C}$ until further analysis.

\section{Histopathology and immunohistochemistry}

After formalin fixation, the tissues were dehydrated in graded ethanol and embedded in paraffin. Sections were then mounted onto the glass slides and stained with hematoxylin and eosin (H\&E) or they were used for immunohistochemistry analysis. For immunohistochemistry, the horseradish peroxidase avidin-biotin complex method with a Vectastain Elite ABC kit (Vector Laboratories, Burlingame, CA, USA) was used. Endogenous peroxidase was inhibited by incubation with freshly prepared $0.3 \%$ hydrogen peroxide with methanol for $30 \mathrm{~min}$. The sections were incubated overnight with rabbit polyclonal anti-GST-P antibody (Medical \& Biological Laboratories, Nagoya, Japan; 1:1,000), mouse monoclonal anti-proliferative cell nuclear antigen (PCNA) antibody (DAKO, Glostrup, Denmark; 1:800) and mouse monoclonal anti-cyclooxygenase (COX-2) antibody (BD Biosciences, Tokyo, Japan; 1:250) at $4^{\circ} \mathrm{C}$, followed by incubation with a biotinylated secondary antibody for $30 \mathrm{~min}$ and with avidin peroxidase conjugate for $30 \mathrm{~min}$ at room temperature. The sections were then developed in $0.05 \% 3,3$ '-diaminobenzidine/hydrogen peroxide as the chromogen. For PCNA staining and COX-2 staining, the deparaffinized tissue sections were placed in an antigen-retrieval solution (0.01 $\mathrm{M}$ citrate buffer, $\mathrm{pH}$ 6.0) for $20 \mathrm{~min}$ in a hot bath at $60^{\circ} \mathrm{C}$ or autoclaved at $121^{\circ} \mathrm{C}$ for 10 min prior to immunohistochemical staining. After staining, the slides were lightly counterstained with hematoxylin. Immunohistochemical analysis of GST-P and PCNA was performed on the liver of each rat from the all groups, but COX-2 immunostaining was performed on the DEN alone and $0.25 \%$ BNF groups.

The numbers and areas of GST-P positive foci $(\geq 0.2$ $\mathrm{mm}$ in diameter) and total areas of the liver sections were quantified using WinRoof software (v5.7.2; Mitani Corp., Fukui, Japan). The number of PCNA positive cells counted under $\times 200$ magnification was expressed as a percentage of total cells counted in 20 randomly selected fields (including altered foci). 
Threshold dose of liver tumor promotion of $\beta$-naphthoflavone

\section{Real-time RT-PCR analyses}

Total RNA was extracted with an RNeasy Mini Kit (QIAGEN, Hilden, Germany), in accordance with the manufacturer's instructions. Reverse transcription was carried out with $2 \mu \mathrm{g}$ RNA for cDNA synthesis using a Thermoscript RT-PCR System kit (Eppendorf Co. Ltd., Tokyo, Japan) in accordance with the manufacturer's protocol. Quantitative real-time RT-PCR with Power SYBR Green PCR Master Mix (Applied Biosystems Japan Ltd., Tokyo, Japan) was performed using a StepOnePlus ${ }^{\mathrm{TM}}$ Real-time PCR System (Applied Biosystems Japan Ltd.). The PCR primers (listed in Table 1) were designed using Primer Express software (Version 3.0; Applied Biosystems Japan Ltd.). The amount of target gene expression was normalized to an endogenous reference (actin, beta) and relative to control was obtained using $2^{-\Delta \Delta \mathrm{Ct}}$ method (Livak and Schmittgen, 2001).

\section{Lipid peroxidation levels}

Oxidative lipid peroxidation was estimated using TBARS. Hepatic TBARS levels were determined using the method described by Ohkawa et al. (1979) with a slight modification. The liver tissue samples (approximately $50 \mathrm{mg}$ ) were homogenized in $450 \mu \mathrm{l}$ of buffer (containing $50 \mathrm{mM}$ Tris-HCl; pH7.4, 1.15\% KCl, $0.2 \mathrm{mM}$ EDTA, $0.1 \mathrm{mM}$ DTT, $0.1 \mathrm{mM}$ Protease Inhibitor Cocktail and 20\% glycerol) using TissueLyser (QIAGEN). Aliquots of $3.0 \mathrm{mg}$ of liver homogenates were mixed with $0.2 \mathrm{ml}$ of $8.1 \%$ sodium dodecyl sulfate and $3.0 \mathrm{ml}$ of $0.4 \%$ thiobarbituric acid in $10 \%$ acetic acid ( $\mathrm{pH} 3.5)$, heated at $95^{\circ} \mathrm{C}$ for $60 \mathrm{~min}$ and then cooled. Each reaction mixture was centrifuged at 3,400 rpm for 10 min after adding $1.0 \mathrm{ml}$ of distilled water and $5.0 \mathrm{ml} \mathrm{n}$-butanol and pyridine $(15: 1, v / v)$. The absorbance of the resulting solution was determined spectrophotometrically at $532 \mathrm{~nm}$, using a Synergy HT Multi-Detection Microplate Reader (BioTek, Winooski, VT, USA). The TBARS levels were expressed as the equivalents of malondialdehyde (MDA) amounts that were produced from 1,1,3,3,-tetramethoxypropane.

\section{Preparation of microsomal fraction}

The microsomal fractions were obtained according to the methods described by Yoshihara et al. (2001). The liver tissue samples (approximately 100 to $130 \mathrm{mg}$ ) were homogenized in $700 \mu \mathrm{l}$ of ice-cold buffer (containing $50 \mathrm{mM}$ Tris- $\mathrm{HCl} ; \mathrm{pH} 7.4,1.15 \% \mathrm{KCl}, 0.2 \mathrm{mM}$ ethylene diamine tetra-acetic acid, $0.1 \mathrm{mM}$ DTT, $0.1 \mathrm{mM}$ Protease Inhibitor Cocktail and $20 \%$ glycerol) using a pestle. The homogenate was centrifuged at 3,000 rpm for $10 \mathrm{~min}$ at $4^{\circ} \mathrm{C}$, and supernatant was centrifuged at 10,000 rpm for $20 \mathrm{~min}$ at $4{ }^{\circ} \mathrm{C}$. The $500 \mu \mathrm{l}$ of supernatant was ultracentrifuged at 51,000 rpm for $90 \mathrm{~min}$. The microsomal pellet was resuspended in the microsome buffer, and protein content of the homogenate was measured using the BCA Protein Assay Kit (Pierce, IL, USA) with bovine serum albumin as a standard.

\section{Microsomal reactive oxygen species production}

NADPH-dependent microsomal ROS production was determined by measuring the oxidation of 2', 7'-dichlorodihydrofluorescein diacetate $\left(\mathrm{H}_{2} \mathrm{DCFDA}\right)$ to its fluorescent product 2', 7'-dichlorofluorescein (DCF) in liver microsomes according to the methods described by Schlezinger et al. (1999). The microsomes (final concentration $0.2 \mathrm{mg} / \mathrm{ml}$ ) were incubated in the dark at $37^{\circ} \mathrm{C}$ for $30 \mathrm{~min}$ in $50 \mathrm{mM}$ Tris- $\mathrm{HCl}(\mathrm{pH} 7.4)$ and $5 \mu \mathrm{M} \mathrm{H}_{2} \mathrm{DCF}-$ DA. In addition, $2.5 \mathrm{mM} \beta$-NADPH was added. In some cases, $0.1 \mathrm{mM}$ SKF-525A (Toronto Research Chemicals, ON, Canada), a well-known inhibitor of cytochrome $\mathrm{P} 450$, and $0.1 \mathrm{mM} \mathrm{H}_{2} \mathrm{O}_{2}$ as a positive control were added to the wells. The fluorescence was monitored every 5 min over $2 \mathrm{hr}$ using a Synergy HT Multi-Detection Microplate Reader (BioTek) with excitation and emission wavelengths of 485 and $528 \mathrm{~nm}$, respectively. The data were then normalized to the control values, with the control expressed as a value of $100 \%$.

\section{Statistical analysis}

All data were expressed as mean plus standard deviation. Numerical data were evaluated using the following methods: Bartlett's test for equal variance was used to determine if the variance was homogenous between the groups. If the variance was homogenous, numerical data were assessed using the Dunnett's multiple test. If a significant difference in variance was observed, the Steel test was used instead.

\section{RESULTS}

\section{Body and liver weights, food intake and histopathology}

In all BNF treated groups, no significant changes were observed in body weight and food intake as compared with the DEN alone group (Table 2).

The absolute and relative liver weights significantly increased in the BNF treated groups. The relative liver weights in the $0.25 \%$ BNF group was approximately 1.4 fold higher than those in the DEN alone group (Table 2).

Histopathologically, BNF induced diffuse hepatocellular hypertrophy with eosinophilic cytoplasm in the groups given $0.06 \%$ BNF or more. Foci of cellular alterations of 
H. Hayashi et al.

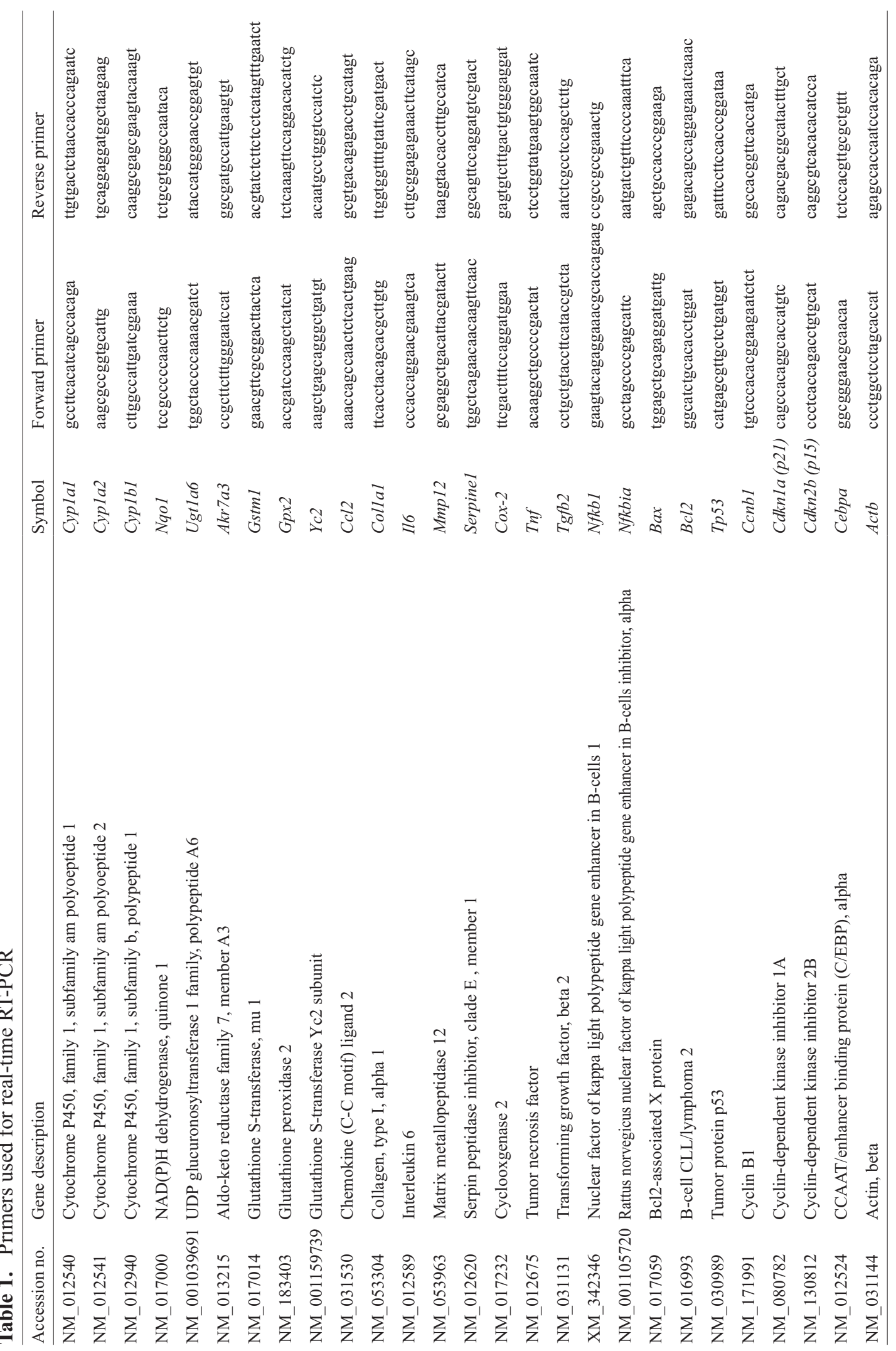

Vol. 37 No. 3 
Threshold dose of liver tumor promotion of $\beta$-naphthoflavone

clear cells, basophilic cells and eosinophilic cells were observed in the DEN alone and BNF treated groups, but the incidence of eosinophilic cells in the groups given $0.06 \%$ BNF or more was clearly higher than the DEN alone group (Table 3).

\section{GST-P-positive foci and PCNA positive cells in the liver}

Immunohistochemical analysis revealed that the number of GST-P-positive foci significantly increased in the 0.06 and $0.25 \%$ BNF groups, and the area of GSTP-positive foci significantly increased in the $0.25 \%$ BNF group (Table 3, Figs. 1a and b). Meanwhile, the number of PCNA-positive cells was not significantly changed between the BNF treated and DEN alone groups (Table 3).

\section{Real-time RT-PCR analyses}

In real-time RT-PCR analysis, a significant dosedependent increase in the expression of Cypla1, Cypla2, Cyp 1 bl and Nqol was observed in the BNF treated groups. BNF also increased the expression of Ugtla6, Akr $7 a 3$ and Gstm 1 in the groups given $0.125 \%$ BNF or more (Table 4). In addition, the expression of Gpx2 and $Y c 2$ significantly increased in the groups given $0.06 \%$ $\mathrm{BNF}$ or more and $0.25 \% \mathrm{BNF}$, respectively.

In addition, Inflammation-related genes such as $\mathrm{Ccl}$, Mmp12, Serpine1 and Cox-2 significantly increased in the $0.25 \%$ BNF group compared with the DEN alone group. The expressions of Colla1, Il6, Tnf, Tgfb2 and $N f k b 1$ showed an increasing tendency in the BNF treated groups compared with the DEN alone group, but these changes were not statistically significant. On the contrary, the expression of Nfkbia significantly decreased in the group given $0.06 \%$ BNF or more.

With regard to the apoptosis-related genes, the expression of $B c l 2$ significantly increased in the groups given $0.125 \%$ $\mathrm{BNF}$ or more, but the expression of Bax was not changed.

In the cell proliferation/cell cycle related genes, the expression of $p 21$ significantly decreased in the groups given $0.125 \%$ BNF or more, but the expression of $p 15$ significantly increased in the $0.25 \%$ BNF group. The expression of $p 53$ showed a decreasing tendency in the BNF treated groups, but there was no significant difference in this gene between the DEN alone and BNF treated groups.

\section{Microsomal ROS production}

To estimate the cellular sources of ROS, NADPHdependent ROS production was measured in liver microsomes (Table 3). The oxidized indicator was not detected in the absence of NADPH. By the addition of NADPH into the microsomal system, ROS production was dramatically enhanced, but no marked changes in ROS production were observed between the BNF treated and DEN alone groups. A well-known inhibitor of cytochrome P450, SKF-525A, inhibited NADPH-dependent ROS production.

\section{Oxidative stress on cellular membrane}

To evaluate whether the oxidative damages to the cellular components occur, TBARS formation was determined in the liver (Table 3 ). There was no remarkable change in TBARS content between the BNF treated and DEN alone groups.

\section{Immunohistochemistry of COX-2 in the liver}

COX-2-positive cells were observed in sinusoid in the liver. Since their size was relatively large, they were considered as Kupffer cells. In the DEN control group, COX-2-positive cells were observed in periportal area of the liver, while the number of COX-2-positive cells in the $0.25 \%$ BNF group increased compared with the DEN alone group (Figs. $2 \mathrm{a}$ and $\mathrm{b}$ ). They were scattered throughout the liver of the BNF group and especially expressed strongly in the periphery of the foci.

\section{DISCUSSION}

Our previous study demonstrated that BNF has a liver tumor promoting activity in rats given $0.5 \% \mathrm{BNF}$ or more (Dewa et al., 2008), and oxidative stress such as overproduction of microsomal ROS, lipid peroxidation and DNA damage was involved in the liver tumor promoting effect of BNF. In addition, treatment of $1 \%$ BNF for 28 weeks to rats induced altered foci and hepatocellular adenomas, and the enhancement of cell proliferation and protection against oxidative stress were related to the BNF-induced hepatocarcinogenesis in rats (Dewa et al., 2009). Furthermore, concurrent apoptosis and regeneration of hepatocytes associated with inflammatory responses including TNF $\alpha$-signaling have been shown to contribute to the tumor promotion of BNF (Kuwata et al., 2011). In the present study, $0.25 \%$ BNF significantly increased the area and number of GST-P-positive foci in the twostage hepatocarcinogenesis model in rats, and we confirmed that $0.25 \% \mathrm{BNF}$ also has a liver tumor promoting activity in rats.

In the real-time RT-PCR, the expression of phase I drug metabolizing enzymes such as Cypla1, Cypla2, Cyp 1 bl and Nqol significantly increased in the groups given $0.03 \%$ BNF or more. The cytochrome P-450 family is generally known to generate ROS as byproducts of microsomal oxidation. CYP1A1 has been reported to be 
H. Hayashi et al.

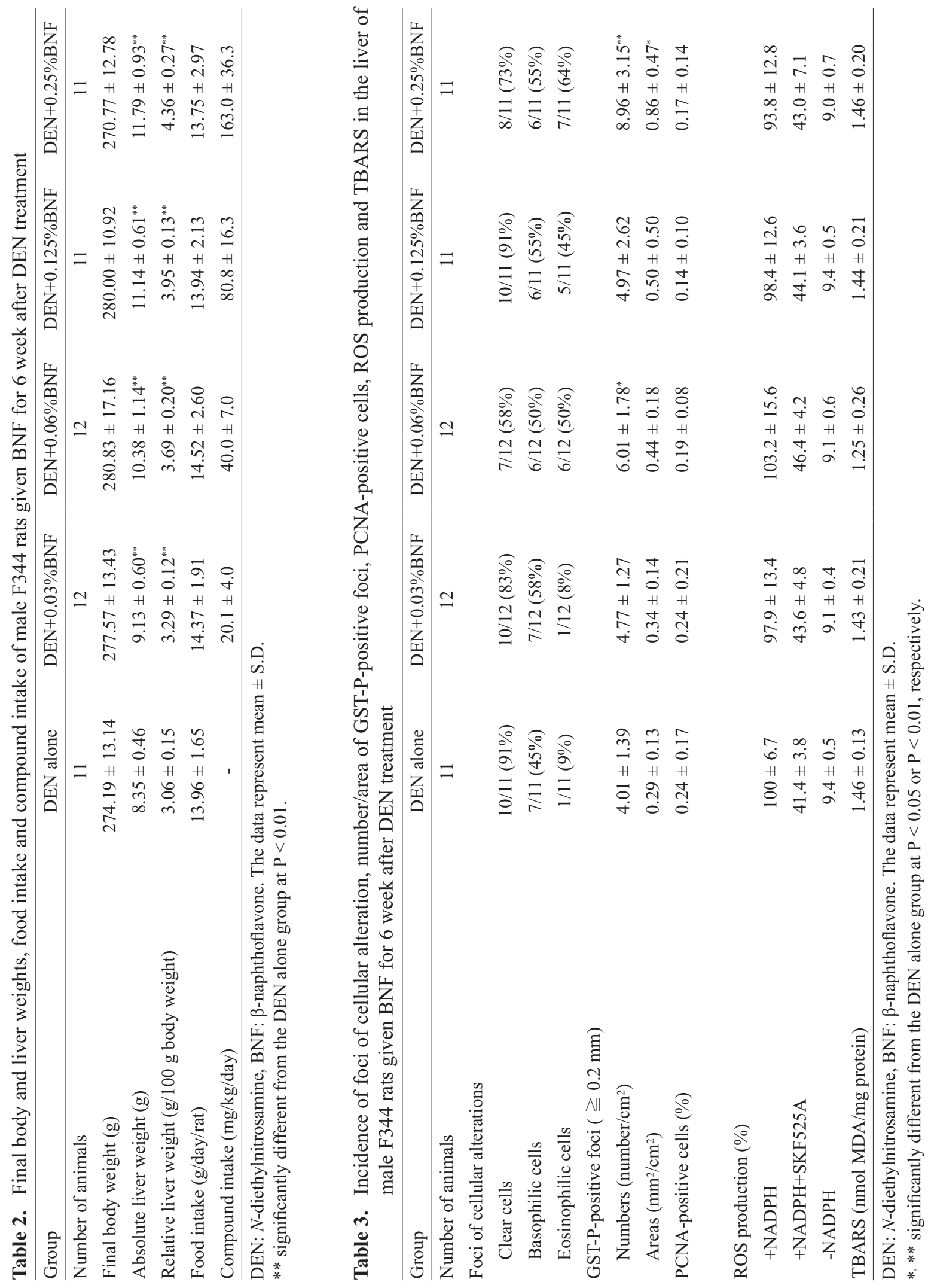

Vol. 37 No. 3 
(a)

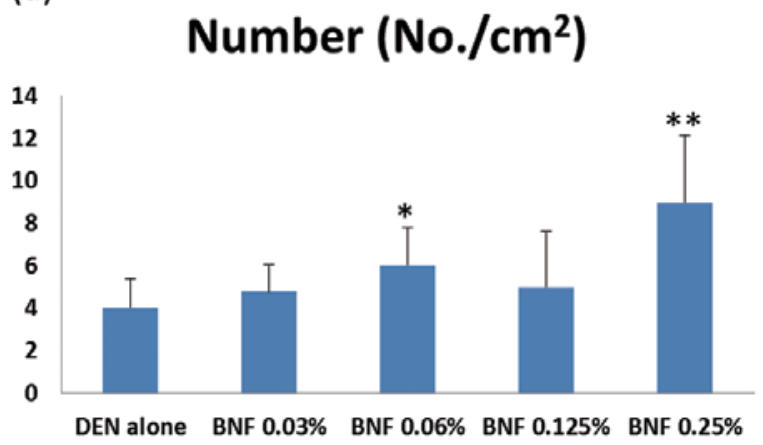

(b)

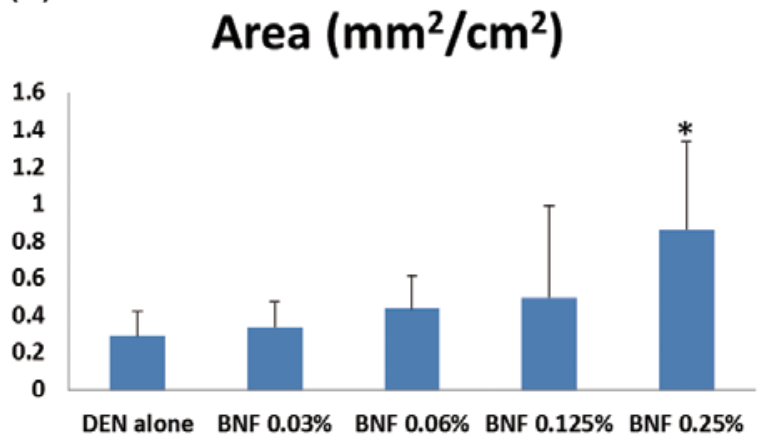

Fig. 1. The number and area of GST-P-positive foci in rats given BNF after DEN initiation. Each graph shows the area (a) and number (b) of GST-P positive foci in the liver of rats administered 0 (DEN alone), $0.03 \%, 0.06 \%, 0.125 \%$ and $0.25 \%$ BNF. Column represents mean + S.D. ${ }^{*},{ }^{* *}$ significantly different from the $\mathrm{DEN}$ alone group at $\mathrm{P}<0.05$ or $\mathrm{P}<0.01$, respectively.
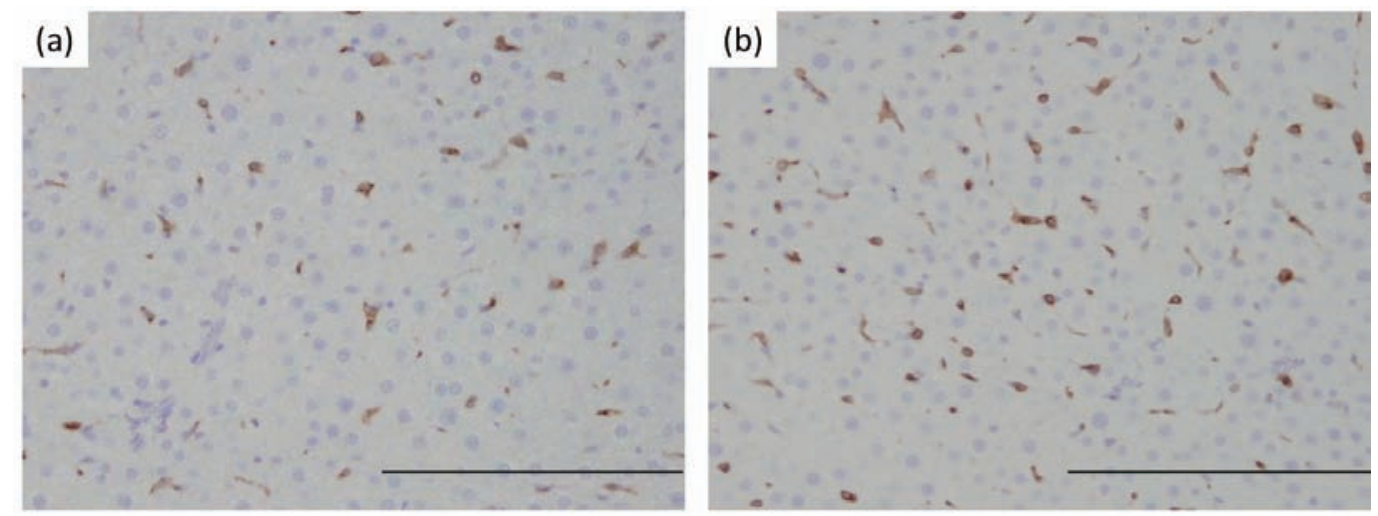

Fig. 2. Immunohistochemical photographs of COX-2 in the liver of rats given BNF after DEN initiation. Each photograph shows COX-2-positive cells in the liver of rats administered DEN alone (a) and $0.25 \%$ BNF (b). Original magnification $\times 200$ (bar; $200 \mu \mathrm{m}$ )

the major enzymes involved in the activation of most of the procarcinogens and promutagens (Guengerich and Shimada, 1991; Puntarulo and Cederbaum, 1998). The upregulation of CYP1A1 and 1A2 isoforms indirectly results in the production of a very large amount of ROS (Puntarulo and Cederbaum, 1998; Nishikawa et al., 2002). Therefore, the upregulation of Cyplal by BNF treatment could have increased the amounts of ROS byproducts due to microsomal oxidation. On the other hand, the detoxification/antioxidant genes including $\mathrm{Akr} 7 \mathrm{a} 3$ and Gstm 1 significantly increased in the groups given $0.125 \% \mathrm{BNF}$ or more, and Gpx2 and $Y_{c} 2$ significantly increased in the groups given $0.06 \% \mathrm{BNF}$ or more and $0.25 \% \mathrm{BNF}$, respectively. These detoxification/antioxidant genes regulated by $\mathrm{Nrf2}$, which is a transcriptional factor, are induced by the activation of Nrf2 by oxidative/electrophile stress (Köhle and Bock, 2007). Our previous study has shown that indole-3-carbinol (I3C) induced hepatocellular tumor promotion in parallel with the induction ratio of Cyplal and subsequent oxidative stress responses in rats (Shimamoto et al., 2011). In the present study, the GST-P-positive foci increased in the $0.25 \%$ BNF together with the induction of Cyplal but not in the groups given $0.125 \% \mathrm{BNF}$ or less despite of the high induction of Cypla1. These results suggest that $0.03 \%$ BNF or more induces ROS production due to the induction of Cyplal but $0.25 \%$ BNF only has a liver tumor promoting activity. However, microsomal ROS production and TBARS known as markers of oxidative stress were not changed in the BNF treated groups compared to the DEN alone group. Oxida- 
H. Hayashi et al.

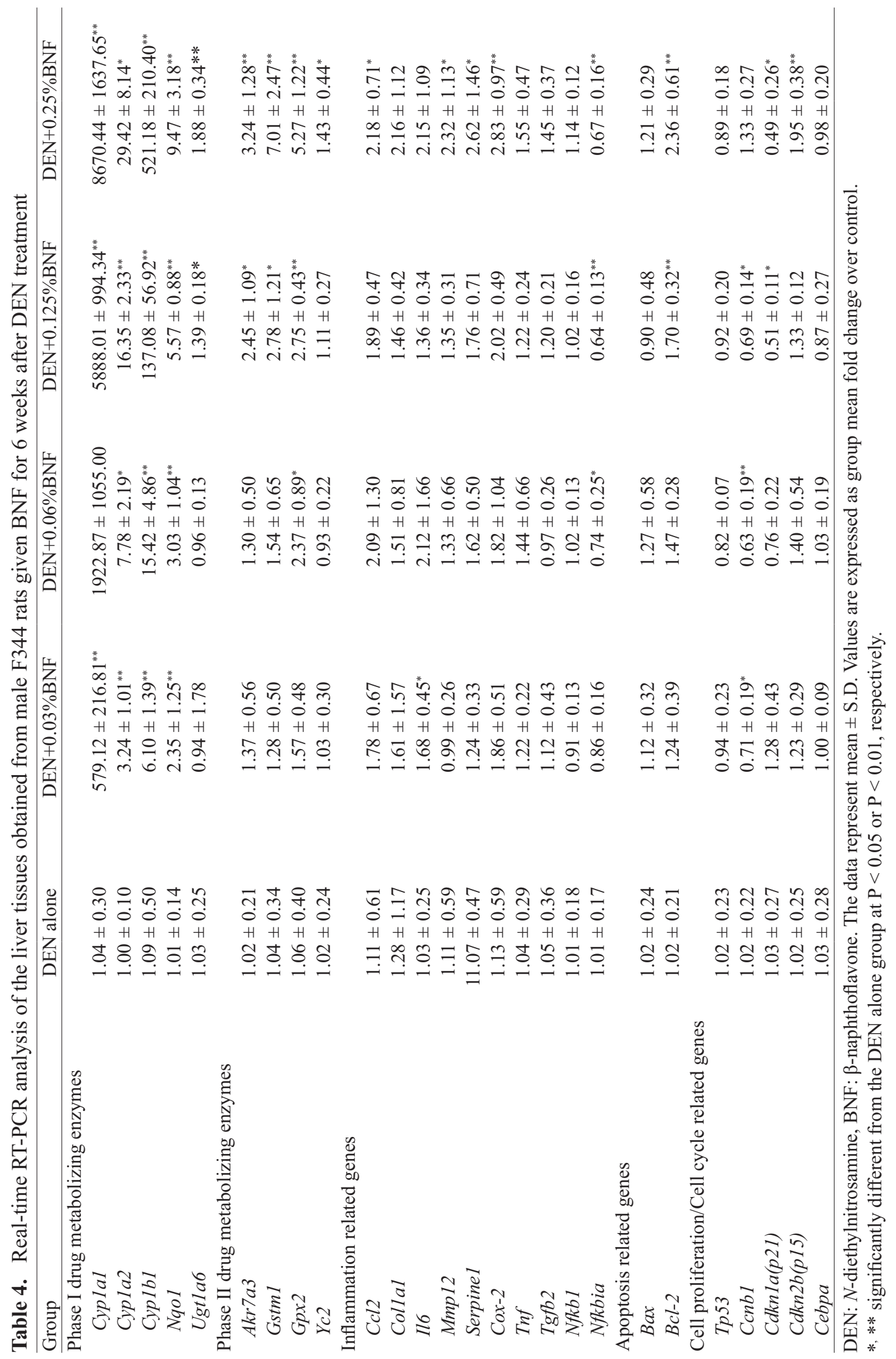

Vol. 37 No. 3 
Threshold dose of liver tumor promotion of $\beta$-naphthoflavone

tive stress occurs in cells or tissues when the amount of ROS produced exceeds antioxidant potential (Klaunig et al., 1998). Therefore, it can be speculated that the antioxidant potential of these Nrf2-related enzymes exceeds the amount of ROS generation in the groups given $0.25 \%$ BNF or less and the ROS produced is accordingly eliminated from these enzymes.

In the present study, Ccl2, Mmp12, Serpinel and Cox-2 significantly increased in the $0.25 \%$ BNF group compared with the DEN alone group. These genes are known to be associated with inflammatory responses (Bertola et al., 2010; Cobos-Correa et al., 2009; Shimada et al., 2010). Tgfb2 induces Serpine1 (Konrad et al., 2009), and Nfkb and Tnf regulate the expression of Ccl2 (Garg and Aggarwal, 2002). In addition, NFKB may regulate the production of prostaglandins (PG) via the COX-2 (Garg and Aggarwal, 2002). In the present study, COX-2-positive cells increased in the $0.25 \%$ BNF group compared with the DEN alone group. In the DEN alone group, COX-2-positive cells were observed in the periportal area of the liver. On the other hand, COX-2-positive cells were expressed throughout the liver in BNF treated groups and especially expressed strongly in the periphery of the foci. We thought that COX-2 was expressed in the Kupffer cells and BNF probably increased the number of Kupffer cells. COX-2 may be involved in the early stage of hepatocarcinogenesis, and increased expression of COX-2 in noncancerous liver tissues has been significantly associated with shorter disease-free survival in patients with hepatocellular carcinomas (Cervello and Montalto, 2006). In tumors, overexpression of COX-2 leads to an increase in PG levels, which affect many mechanisms involved in carcinogenesis such as angiogenesis, inhibition of apoptosis, stimulation of cell growth as well as the invasiveness and metastatic potential of tumor cells (Cervello and Montalto, 2006). In our previous study, enzymatically modified isoquercitrin (EMIQ) suppressed the liver tumor-promoting activity of BNF in rats through suppression of COX-2 (Shimada et al., 2010). In addition, Kuwata et al. (2011) performed an additional mechanistic study on liver tumor promotion of BNF and clarified that BNF-induced oxidative stress cause single liver cell toxicity, allowing subsequent concomitant apoptosis and regeneration involving inflammatory responses including TNF-signaling, contributing to tumor promotion. Thus, inflammation is considered to be involved in the liver tumor promoting effect of $\mathrm{BNF}$ in rats.

$\mathrm{Bcl} 2$ is a proto-oncogene in blocking programed cell death rather than promoting proliferation, and a ratio of Bcl2/Bax determines the survival or death of cells following an apoptotic stimulus (Korsmeyer et al., 1993). In addi- tion, $\mathrm{Bcl} 2$ prevents oxidative damage to cellular constituents including cell membranes (Korsmeyer et al., 1993). In the present study, the expression of $B c l 2$ significantly increased in the groups given $0.125 \% \mathrm{BNF}$ or more, but the expression of Bax was not changed in the BNF treated groups. Therefore, the exact mechanism of upregulated $\mathrm{Bcl} 2$ is not clear, but $\mathrm{Bcl} 2$ may be induced by ROS that was not completely eliminated from the antioxidant enzymes, and up-regulation of Bcl2 probably leans the balance between cell survival and apoptosis to cell survival.

In cell proliferation activity, PCNA-positive cells were not significantly fluctuated in the BNF treated groups. P21 is an inhibitor of cyclin/cyclin-dependent kinase (CDK) complexes, and p21 induction is mediated by p53 (Roninson, 2002). Decreased expression of $\mathrm{p} 21$ protein contributed to the cell proliferation in altered foci and adenomas induced by BNF (Dewa et al., 2009). In our study, the expression of $p 21$ decreased and the expression of p53 slightly, but not significantly, decreased in the $0.25 \%$ BNF group. On the contrary, the expression of $p 15$, one of CDK inhibitors which arrest cells in the G1 phase of the cell cycle, significantly increased in the $0.25 \% \mathrm{BNF}$ group (Baldi et al., 2011). Therefore, it can be considered that promotion and suppression of cell proliferation concurrently occurred in the highest dose group of BNF, and no marked cell proliferation is therefore induced in the BNF treated groups.

In conclusion, the result of our study showed that $0.25 \% \mathrm{BNF}$ is the threshold dose for liver tumor promotion. The fact that oxidative stress was not induced in the doses of BNF used in this study while inflammationrelated genes were upregulated and COX-2 protein were induced in the $0.25 \%$ BNF group strongly suggests that inflammation is involved in the liver tumor promoting effect of BNF in rats.

\section{ACKNOWLEDGMENT}

This study was partly supported by a grant in-aid for research on the safety of veterinary drugs in food of animal origin from the Ministry of Health, Labour and Welfare of Japan (H22-shokuhin-ippan-007).

\section{REFERENCES}

Asare, G.A., Mossanda, K.S., Kew, M.C., Paterson, A.C., KahlerVenter, C.P. and Siziba, K. (2006): Hepatocellular carcinoma caused by iron overload: a possible mechanism of direct hepatocarcinogenicity. Toxicology, 219, 41-52.

Baldi, A., De Luca, A. and Esposito, V., Campioni, M., Spugnini, E.P. and Citro, G. (2011): Tumor suppressors and cell-cycle proteins in lung cancer. Patholog. Res. Int. Epub 2011 Oct 5. 


\section{H. Hayashi et al.}

Bertola, A., Bonnafous, S., Anty, R., Patouraux, S., Saint-Paul, M.C., Iannelli, A., Gugenheim, J., Barr, J., Mato, J.M., Le, Marchand-Brustel, Y., Tran, A. and Gual, P. (2010): Hepatic expression patterns of inflammatory and immune response genes associated with obesity and NASH in morbidly obese patients. PLoS One., 5, e13577.

Brown, J.P. and Dietrich, P.S. (1979): Mutagenicity of plant flavonols in the Salmonella/mammalian microsome test: activation of flavonol glycosides by mixed glycosidases from rat cecal bacteria and other sources. Mutat. Res., 66, 223-240.

Cervello, M. and Montalto, G. (2006): Cyclooxygenases in hepatocellular carcinoma. World J. Gastroenterol., 12, 5113-5121.

Cobos-Correa, A., Trojanek, J.B., Diemer, S., Mall, M.A. and Schultz, C. (2009): Membrane-bound FRET probe visualizes MMP12 activity in pulmonary inflammation. Nat. Chem. Biol., 5, 628-630.

Dewa, Y., Nishimura, J., Muguruma, M., Jin, M., Saegusa, Y., Okamura, T., Tasaki, M., Umemura, T. and Mitsumori, K. (2008): Beta-Naphthoflavone enhances oxidative stress responses and the induction of preneoplastic lesions in a diethylnitrosamine-initiated hepatocarcinogenesis model in partially hepatectomized rats. Toxicology, 244, 179-189.

Dewa, Y., Nishimura, J., Jin, M., Kawai, M., Saegusa, Y., Harada, T., Shibutani, M. and Mitsumori, K. (2009): Molecular expression analysis of beta-naphthoflavone-induced hepatocellular tumors in rats. Toxicol. Pathol., 37, 446-455.

Garg, A. and Aggarwal, B.B. (2002): Nuclear transcription factorkappaB as a target for cancer drug development. Leukemia., 16, 1053-1068.

Guengerich, F.P. and Liebler, D.C. (1985): Enzymatic activation of chemicals to toxic metabolites. Crit. Rev. Toxicol., 14, 259-307.

Guengerich, F.P. and Shimada, T. (1991): Oxidation of toxic and carcinogenic chemicals by human cytochrome P-450 enzymes. Chem. Res. Toxicol., 4, 391-407.

Ito, N., Tamano, S. and Shirai, T. (2003): A medium-term rat liver bioassay for rapid in vivo detection of carcinogenic potential of chemicals. Cancer Sci., 94, 3-8.

Klaunig, J.E., Xu, Y., Isenberg, J.S., Bachowski, S., Kolaja, K.L., Jiang, J., Stevenson, D.E. and Walborg, E.F.Jr. (1998): The role of oxidative stress in chemical carcinogenesis. Environ. Health. Perspect., 106, Suppl. 1, 289-295.

Köhle, C. and Bock, K.W. (2007): Coordinate regulation of Phase I and II xenobiotic metabolisms by the Ah receptor and Nrf2. Biochem. Pharmacol., 73, 1853-1862.

Konrad, L., Scheiber, J.A., Schwarz, L., Schrader, A.J. and Hofmann, R. (2009): TGF-beta1 and TGF-beta2 strongly enhance the secretion of plasminogen activator inhibitor-1 and matrix metalloproteinase- 9 of the human prostate cancer cell line PC-3. Regul. Pept., 155, 28-32.

Korsmeyer, S.J., Shutter, J.R., Veis, D.J., Merry, D.E. and Oltvai, Z.N. (1993): Bcl-2/Bax: a rheostat that regulates an anti-oxidant pathway and cell death. Semin. Cancer Biol., 4, 327-332.

Kuwata, K., Shibutani, M., Hayashi, H., Shimamoto, K., Hayashi, S.M., Suzuki, K. and Mitsumori, K. (2011): Concomitant apoptosis and regeneration of liver cells as a mechanism of livertumor promotion by $\beta$-naphthoflavone involving TNF $\alpha$-signaling due to oxidative cellular stress in rats. Toxicology, 283, 8-17.

Lin, P.H., Lin, C.H., Huang, C.C., Chuang, M.C. and Lin, P. (2007): 2,3,7,8-Tetrachlorodibenzo-p-dioxin (TCDD) induces oxidative stress, DNA strand breaks, and poly(ADP-ribose) polymerase-1 activation in human breast carcinoma cell lines. Toxicol. Lett., 172, 146-158.

Livak, K.J. and Schmittgen, T.D. (2001): Analysis of relative gene expression data using real-time quantitative PCR and the 2(-Delta Delta C(T)) Method. Methods., 25, 402-408.

Moriya, K., Nakagawa, K., Santa, T., Shintani, Y., Fujie, H., Miyoshi, H., Tsutsumi, T., Miyazawa, T., Ishibashi, K., Horie, T., Imai, K., Todoroki, T., Kimura, S. and Koike, K. (2001): Oxidative stress in the absence of inflammation in a mouse model for hepatitis $\mathrm{C}$ virus-associated hepatocarcinogenesis. Cancer Res., 61, 4365-4370.

Nishikawa, T., Wanibuchi, H., Ogawa, M., Kinoshita, A., Morimura, K., Hiroi, T., Funae, Y., Kishida, H., Nakae, D. and Fukushima, S. (2002): Promoting effects of monomethylarsonic acid, dimethylarsinic acid and trimethylarsine oxide on induction of rat liver preneoplastic glutathione S-transferase placental form positive foci: a possible reactive oxygen species mechanism. Int. J. Cancer, 100, 136-139.

Ohkawa, H., Ohishi, N. and Yagi, K. (1979): Assay for lipid peroxides in animal tissues by thiobarbituric acid reaction. Anal. Biochem., 95, 351-358.

Prochaska, H.J. and Talalay, P. (1988): Regulatory mechanisms of monofunctional and bifunctional anticarcinogenic enzyme inducers in murine liver. Cancer Res., 48, 4776-4782.

Puntarulo, S. and Cederbaum, A.I. (1998): Production of reactive oxygen species by microsomes enriched in specific human cytochrome P450 enzymes. Free Radic. Biol. Med., 24, 1324-1330.

Roninson, I.B. (2002): Oncogenic functions of tumour suppressor $\mathrm{p} 21$ (Waf1/Cip1/Sdi1): association with cell senescence and tumour-promoting activities of stromal fibroblasts. Cancer Lett., 179, 1-14.

Schlezinger, J.J., White, R.D. and Stegeman, J.J. (1999): Oxidative inactivation of cytochrome P-450 1A (CYP1A) stimulated by 3,3',4,4'-tetrachlorobiphenyl: production of reactive oxygen by vertebrate CYP1As. Mol. Pharmacol., 56, 588-597.

Shimada, Y., Dewa, Y., Ichimura, R., Suzuki, T., Mizukami, S., Hayashi, S.M., Shibutani, M. and Mitsumori, K. (2010): Antioxidant enzymatically modified isoquercitrin suppresses the development of liver preneoplastic lesions in rats induced by beta-naphthoflavone. Toxicology, 268, 213-218.

Shimamoto, K., Dewa, Y., Kemmochi, S., Taniai, E., Hayashi, H., Imaoka, M., Shibutani, M. and Mitsumori, K. (2011): Relationship between CYP1A induction by indole-3-carbinol or flutamide and liver tumor-promoting potential in rats. Arch. Toxicol., 85, 1159-1166.

Shoda, T., Mitsumori, K., Onodera, H., Toyoda, K., Uneyama, C., Takada, K. and Hirose, M. (2000a): Liver tumor-promoting effect of beta-naphthoflavone, a strong CYP $1 \mathrm{~A} 1 / 2$ inducer, and the relationship between CYP $1 \mathrm{~A} 1 / 2$ induction and $\mathrm{C} \times 32$ decrease in its hepatocarcinogenesis in the rat. Toxicol. Pathol., 28, 540-547.

Shoda, T., Mitsumori, K., Takahashi, T., Horiuchi, K., Yamazaki, Y., Suzuki, Y., Katsuda, Y., Yokomoto, Y. and Kurumi, M. (2000b): Liver tumor promotion by $\beta$-naphthoflavone, a strong CYP $1 \mathrm{~A} 1 / 2$ inducer, in a 28 week two-stage rat hepatocarcinogenesis model using diethylnitrosamine as an initiator. J. Toxicol. Pathol., 13, 37-43.

Trush, M.A. and Kensler, T.W. (1991): An overview of the relationship between oxidative stress and chemical carcinogenesis. Free Radic. Biol. Med., 10, 201-209.

Wiseman, H. and Halliwell, B. (1996): Damage to DNA by reactive oxygen and nitrogen species: role in inflammatory disease and progression to cancer. Biochem. J., 313, 17-29.

Yoshihara, S., Makishima, M., Suzuki, N. and Ohta, S. (2001): Metabolic activation of bisphenol A by rat liver S9 fraction. Toxicol. Sci., 62, 221-227.

Vol. 37 No. 3 